\title{
Transcription regulatory factor expression in T-helper cell differentiation pathway in eutopic endometrial tissue samples of women with endometriosis associated with infertility
}

\author{
HALYNA D. KOVALI, VALENTYNA V. CHOPYAK', OLEKSANDR M. KAMYSHNYI', \\ MACIEJ K. KURPISZ ${ }^{4}$ \\ ${ }^{1}$ Bukovinian State Medical University, Chernivtsi, Ukraine \\ ${ }^{2}$ Department of Clinical Immunology and Allergology, Danylo Halytsky Lviv National Medical University, Lviv, Ukraine \\ ${ }^{3}$ Zaporizhia State Medical University, Zaporizhia, Ukraine \\ ${ }^{4}$ Institute of Human Genetics, Polish Academy of Sciences, Poznan, Poland
}

\begin{abstract}
Endometriosis is a disease of epidemiological gravity of unknown primary reason. A complex of constitutional factors including the immune system has been considered as its background.

The aim of the study was to identify Th1 and Th2 cells as well as the T-regulatory subset in the endometrium of women with endometriosis associated with infertility upon transcription factors expression. Expression of T-bet, GATA3, and Foxp3 genes was examined using a method of polymerase chain reaction (PCR) in the eutopic endometrial samples of 20 women with endometriosis associated with infertility and 20 women with infertility of tubal origin. An increase in mRNA expression for T-bet and GATA3 with prevailing $m R N A$ level for T-bet and a decrease in Foxp3 expression were observed. In conclusion, the revealed changes in expression of transcription factors may indicate the imbalance between T-helper cells of the Th1 and Th2 type and elimination of regulatory function of T-cells, which can be one of the causes of endometriosis predisposing to the development of infertility associated with this disease.
\end{abstract}

Key words: endometriosis, infertility, T-helper cells, T-bet, GATA3, Foxp3.

(Centr Eur J Immunol 2018; 43 (1): 90-96)

\section{Introduction}

Endometriosis is a disease characterised by the benign growth of ectopic tissue similar to the physiological endometrium (by its morphological and functional characteristics) beyond the uterine cavity, often associated with hormonal disorders and genetic constitution [1]. The frequency and spread of the disease is epidemic: endometriosis is diagnosed in $7-59 \%$ of women with chronic pelvic pain, in $20-30 \%$ of women with fertility problems, and in $2-22 \%$ of asymptomatic women $[2,3]$. The morbidity rate in endometriosis is about $10 \%$ among the general population of women $[1,2]$. The frequency of primary and secondary female infertility in the case of endometriosis, according to the data of various authors, ranges between 40 and 80\% [4-7]. 30-40\% of patients with endometriosis were found to suffer from infertility, and about $30 \%$ from miscarriage syndrome [5, 6].

The frequency of this disorder and its association with infertility makes endometriosis a subject of intense study, diagnosis, and treatment. Despite several studies concerning this problem, the aetiology and pathogenesis of endometriosis is not clear and remains at the level of theory in many aspects $[8,9]$. In this context endometriosis is often called a "disease-enigma" [10]. However, considering the fact that the disease itself is a benign ectopia, it is understandable that immune imbalance occupies a leading position in the pathogenesis of endometriosis because the main task of the immune system is maintenance of homeostasis, including the control of various ectopic formations [8-11].

In our view, an important issue in the pathogenesis of endometriosis is to understand the paradigm of Th1/Th2 cells, which will mean not only better pathogenetic awareness but also a possibility to conduct efficient therapy. It is essential that the evidence for Th1/Th2 cell correlation with many disorders as well as Th1/Th2 cytokine interplay in patients with endometriosis are investigated. For example, it was found in the case of endometriosis, that typical Th1 cytokines - INF- $\gamma$ and IL-2 - increased in the peritone-

Correspondence: Prof. Maciej K. Kurpisz, Department of Reproductive Biology and Stem Cells, Institute of Human Genetics, Polish Academy Sciences, 32 Strzeszynska St., 61-049 Poznań, Poland, e-mail: kurpimac@man.poznan.pl Submitted: 14.07.2016; Accepted: 03.01.2017 
al fluid [12], TNF- $\alpha$ concentration correlated with the stage of endometriosis [11, 12], and introduction of recombinant human TNF-inhibitor reduced the size of the ectopic sites [13]. IL-12 abrogated experimental endometriosis in rats [14] or under natural conditions [15]. On the other hand, there are studies indicating the intensification of proliferation of the endometrial stromal cells under the influence of typical Th2 cytokine - IL- 4 - and a decrease of endometrial growth under the influence of anti-IL-4 monoclonal antibody [16]. Some research has indicated that endometriosis reveals features of autoimmune disease connected with Th2 prevalence [17]. Therefore, the development of endometriosis is accompanied by disordered cytokines of both helper types, and it is still unknown whether endometriosis is typical for Th1- or Th2-mediated disease.

In recent years our knowledge concerning T-helper 1 and 2 cells has improved, and new information has appeared concerning their dichotomy. At present it is envisaged that there are at least four sub-populations of $\mathrm{CD}^{+}$ T-cells: T-helper of the first type (Th1), T-helper of the second type (Th2), T-helper17 (Th17), and regulatory T-cells - CD4 ${ }^{+}$CD $25^{+}$Foxp3 $^{+}$(Treg) [18-20]. Pro-inflammatory Th17 cells were shown to produce high concentrations of IL-17A, IL-17F, IL-6, and TNF- $\alpha$ cytokines [21]. Contrary to previous approaches to identify T-helpers on the basis of their ability to produce cytokines their actual definition consists of number of molecular mechanisms governing T-helper cell effector differentiation [18-20, 22]. Molecular mechanisms, by which antigenic stimulation of $\mathrm{T}$-cell receptor results in differentiation of naive T-cells in the direction of Th1 or Th2, have been an area of focus in recent years. Clonal expansion and differentiation of naive $\mathrm{T}$-cells are known to be complex processes regulated by the network of transcription factors (TF) and transcription activators - signal transducers in the cytoplasm and activators of transcription (STAT) [23, 24]. To differentiate every subtype of the cells, their own TF and STAT are essential, being able to intensify or inhibit differentiation of certain helper cell subtypes. For example, to differentiate into Th1 cells T-bet (T-box), STAT-1 and iSTAT-4 are necessary, while to differentiate into Th2, GATA3 and iSTAT-5 are essential. In order to differentiate into Th17, RORgt and STAT-3 are required, while to differentiate into nTreg and iTreg cells, Foxp3 (forkhead box protein P3) and STAT-5 are necessary [18, 22, 23, 26-29]. To coordinate a complete transcription program in addition to previously mentioned factors, other transcription regulators must also participate. T-cell differentiation is characterised by a considerable degree of flexibility and elasticity essential to its completion, which has been demonstrated both in in vitro and in vivo conditions [18, 22, 23, 30, 31].

Studies on $\mathrm{TF} / \mathrm{s}$ and their functions, e.g. in respect to T-bet/GATA3, were found to reflect more objectively the Th1/Th2 differentiation process, but not just measuring TFs of one or another type (Th1 or Th2), or detecting the relevant cytokines $[32,33]$. It seems most appropriate to examine also the balance among Th1/Th2/Th17/Treg subsets at the level of the selected transcription factors.

Great attention was dedicated to the study of transcription factors in respect to the regulation of differentiation of Th human cells into Th1/Th2/Th17/Treg. An imbalance between Th1/Th2 and Th17/Treg cell subsets was found to play an important role in a number of physiological and pathological conditions, such as allergy, autoimmunity, haematological diseases, and tumours $[34,35]$. Of course, Th1/ Th2 and Th17/Treg cell subsets also play an important role in reproductive processes $[36,37]$. Although, there are very few studies dealing with the problem of transcription factors in the case of endometriosis, this topic has not been clarified, and therefore it inspired the aim of this research [38].

The objective of this study was to detect Th1/Th2 and other regulatory lymphocyte subsets on the basis of the expression of transcription factors (T-bet, GATA3, Foxp3) in the eutopic endometrial tissue samples of women with endometriosis associated with infertility.

\section{Material and methods}

All the women recruited to the study underwent careful anamnesis, physical and laboratory examinations (including microbiological screening) as well as radiological, ultrasound, and endoscopic evaluations, on the basis of which the final diagnosis was made.

Women manifested infertility (at the level of conception) for at least 2 years (average duration of infertility was $5.04 \pm 2.2$ years). Then the groups were subdivided (laparoscopy vs. hysteroscopy) into 20 infertile women with endometriosis (target group) and 20 women with infertility of a tubal origin (control group).

Classification of endometriosis and its respective stages was conducted in respect to the revised classification of endometriosis (American Society for Reproductive Medicine, r-ASRM) and based on laparoscopic investigations and histopathological sampling, and included the following: Stage 1 ("minimal") endometriosis diagnosed in $30 \%$ of patients $(n=6)$, Stage 2 ("mild") - 25\% $(n=5)$, Stage 3 ("moderate") - 30\% $(n=6)$, and Stage 4 ("severe") - $15 \%$ of patients $(n=3)$. A group with "tubal factor" infertility was recruited based on diagnostic hysteroscopy excluding a previous active endometriotic process in the pelvis minor (laparoscopy). The biological material for the study originated from the tissue sampling of eutopic endometrium.

The research requirements corresponded to the rules of biomedical investigations approved by the Local Bioethical Committee, Bukovinian State Medical University, as well as the Local Medical Committee of the Centre of Infertility Treatment (Chernivtsi), in which the patients were treated. All the examinations were performed with prior informed consent obtained from the patients assuring their confidentiality. 
mRNA for studies on T-bet (T-box 21), GATA3, and Foxp3 gene expression was extracted from the eutopic endometrial tissue samples and reversely transcribed, and then polymerase chain reaction (PCR) was performed. First, the samples to be studied were grinded and homogenised, then they were deparaffinised in xylene, and dehydration was made in decreasing concentrations of ethanol $(100 \%, 96 \%, 70 \%)$.

Total RNA was obtained using "Trizol RNA Prep 100” (Isogen Lab., LTD, Russia) containing Trizol reagent (lytic reagent containing denaturating guanidine thiocyanate and phenol with $\mathrm{pH}=4.0$ ) and ExtraGene $\mathrm{E}$ (suspension of ion exchange mixture). RNA was extracted following the manufacturer's protocol. Endometrial samples were standardised according to the quantity of total RNA extracted equaling to $10 \mu \mathrm{g}$ per analysed sample. The total RNA sample was subjected to further purification with Oligo (dT) 25 (Invitrogen, USA) in order to obtain the mRNA fraction.

Reverse transcription and DNA preparation were performed by means of OT-1 kit from the "Syntol" company (Russia). The reaction mixture of total $25 \mu$ l volume contained: $1 \mu \mathrm{l}$ of Random- 6 primer, $2 \mu$ total RNA, $8.5 \mu \mathrm{l}$ deionised $\mathrm{H}_{2} \mathrm{O}$, purified of nucleases, $12.5 \mu \mathrm{l} 2.5 \times$ nucleotide mixture, and $1 \mu$ reverse transcriptase MMLV-RT. Reverse transcription was conducted at $45^{\circ} \mathrm{C}$ for 45 minutes followed by heating to inactivate MMLV-RT for 5 minutes at $92^{\circ} \mathrm{C}$. The obtained cDNA was immediately used in polymerase chain reaction (PCR) at the volume of 1-10 $\mu$ or kept at $-70^{\circ} \mathrm{C}$ until further use.

To detect the expression level of genes under study the CFX96 ${ }^{\mathrm{TM}}$ Real-Time PCR Detection Systems (Bio-Rad Laboratories, Inc., USA) and the kit of Maxima SYBR Green/ROX qPCR Master Mix (2X) (Thermo Scientific, USA) were applied. Final reaction mixture for amplification included the SYBR Green, DNA-polymerase Maxima Hot Start Taq DNA Polymerase, per $0.2 \mu$ of specific primers, $1 \mu \mathrm{l}$ of matrix (cDNA). The reaction mixture was brought to a total volume of $25 \mu \mathrm{l}$ by adding deionised $\mathrm{H}_{2} \mathrm{O}$.

Specific sets of selected primers (5'-3') for the study as well as the reference gene were selected by using Primer Blast software (www.ncbi.nlm.nih.gov/tools/primer-blast), and they were produced by Metabion (Germany) (Table 1).
Before PCR amplification was started, an initial denaturation for 10 minutes at $95^{\circ} \mathrm{C}$ was performed. Amplification consisted of 45-50 cycles and was carried out under the following conditions: denaturation at $95^{\circ} \mathrm{C}, 15 \mathrm{sec}$, annealing $-59-61^{\circ} \mathrm{C}, 30-60 \mathrm{sec}$, and elongation $-72^{\circ} \mathrm{C}$, $30 \mathrm{sec}$. As a reference gene to detect a relative value of the examined genes expression, the glyceraldehyde-3-phosphate dehydrogenase (GAPDH) encoding gene was selected. A normalised cDNA amount of genes under study was defined by means of ${ }^{\Delta \wedge} \mathrm{Ct}$ method. Statistical analysis of PCR results was conducted using CFX Manager ${ }^{\mathrm{TM}}$ (BioRad, USA) software.

\section{Results}

The genes under study are listed in Table 1 with starter sequences and basic molecular characteristics.

Relative cDNA levels for T-bet, GATA3, and Fox3 genes are summarised in Table 2 , showing significant differences between women with endometriosis associated with infertility and the control group.

However, T-bet and GATA3 genes revealed significant increase in the tested vs. the control group, while Foxp3 gene expression revealed an inverse relationship.

The most accentuated difference between tested and control groups (group A vs. group B) was noted for T-bet gene (Fig. 1).

\section{Discussion}

The results of mRNA transcription for Foxp3, T-bet, and GATA3 genes in the eutopic endometrial samples of women with endometriosis and associated infertility compared with a control group of women are illustrated in Table 2. Thus Table 2 shows that the results obtained indicated significant changes in expression of all the examined transcription factor genes in the eutopic endometrial samples of women with endometriosis associated with infertility when compared to the control group. In particular, the level of mRNA for the T-bet gene increased 3.76 fold $(p<0.01)$ as compared to the controls (Fig. 1).

Table 1. The designed primers sequences

\begin{tabular}{|c|c|c|c|c|}
\hline $\begin{array}{l}\text { Gene } \\
\text { detected }\end{array}$ & Primer sequences & Melting temperature $\left({ }^{\circ} \mathrm{C}\right)$ & Product length (bp) & Exon junction \\
\hline \multirow[t]{2}{*}{ Foxp3 } & F: 5'-TCTGCACCTTCCCAAATCCC-3' & 59.96 & 48 & $730 / 731$ \\
\hline & R: 5'-AAAGGGTGCTGTCCTTCCTG-3' & 59.89 & & \\
\hline \multirow{2}{*}{$\begin{array}{l}\text { T-box } 21 \\
\text { (T-bet) }\end{array}$} & F: 5'-CCGTGACTGCCTACCAGAAT-3' & 59.46 & 40 & $1138 / 1139$ \\
\hline & R: 5'-TTCAGCTGAGTAATCTCGGCA-3' & 59.18 & & \\
\hline \multirow[t]{2}{*}{ GATA3 } & F: 5'-GATGCAAGTCCAGGCCCAA-3' & 60.3 & 51 & $1335 / 1336$ \\
\hline & R: 5'-CACACTCCCTGCCTTCTGTG-3' & 60.6 & & \\
\hline
\end{tabular}


Table 2. Relative cDNA level for T-bet, GATA3, and Foxp3 genes in the endometrial samples of women with endometriosis and infertility in comparison to respective control group

\begin{tabular}{lcccc}
\hline \multirow{2}{*}{ No. } & Groups of patients & \multicolumn{3}{c}{ mRNA level of transcription factors genes } \\
\cline { 3 - 5 } & & T-bet & GATA3 & Foxp3 \\
\hline 1 & $\begin{array}{c}\text { Women with endometriosis } \\
\text { associated with infertility }(n=20)\end{array}$ & $3.76 \pm 0.54$ & $2.86 \pm 0.39$ & $0.35 \pm 0.01$ \\
\hline 2 & Control group $(n=20)$ & $1.00 \pm 0.11$ & $1.01 \pm 0.10$ & $1.00 \pm 0.12$ \\
\hline$p$ level & & $<0.01$ & $<0.01$ & $<0.01$ \\
\hline$p<0.01-$ significant difference. Normalisation was performed by using ${ }^{\triangle \Lambda}$ Ct method with reference gene, GAPDH
\end{tabular}

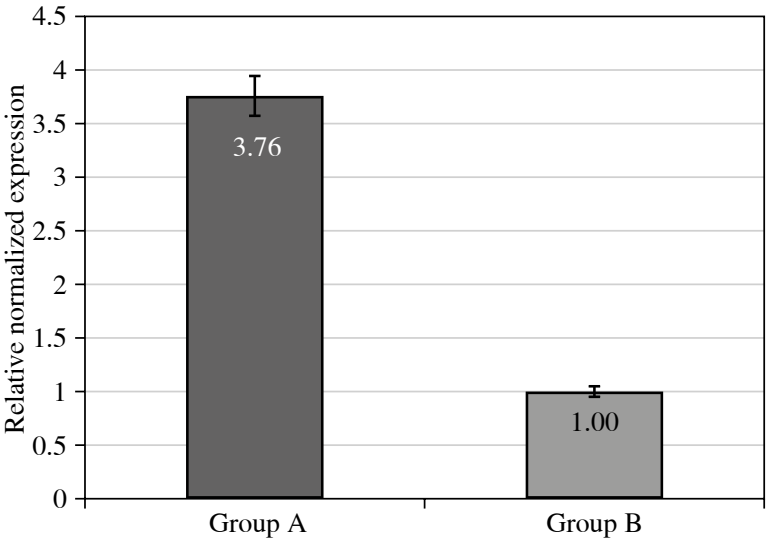

Fig. 1. Relative cDNA levels for T-bet gene expression in eutopic endometrium of women with endometriosis and associated infertility (Group A), and control group (Group B). Group A vs. Group B at $p$ level $<0.01$

The results obtained indicate increased T-bet gene expression, which may be correlated with the increase of Th1 helper cells in the endometrium of women with endometriosis associated with infertility. As is documented in the literature, differentiation of nadve T-cells in direction to Th1 cells is promoted by two main signals - one of them with participation of IL-12/STAT4 and the second one with participation of IFN- $\gamma / \mathrm{STAT} 1 / \mathrm{T}$-bet [39-42]. It corresponds to well-known studies demonstrating an increase of IL-12 and IFN- $\gamma$ concentrations in the peritoneal fluid of patients with endometriosis [43]. There are also studies showing that the presence of IL-12 increased with the expression of transcription factor gene, T-bet [24]. This observation may correspond to the results obtained in our previous studies demonstrating increased IL-12 concentration in the peritoneal fluid samples of patients with endometriosis [44]. The increase in mRNA transcription for the T-bet gene in endometrium is accompanied by increased concentration of cytokines typical for Th1 cells (IL-2, INF- $\gamma$, TNF- $\alpha$ ) in peritoneal fluid, which is supported by the literature as well as by the results previously obtained in a group of patients with endometriosis (the results previously obtained with the same group of patients indicated a significant

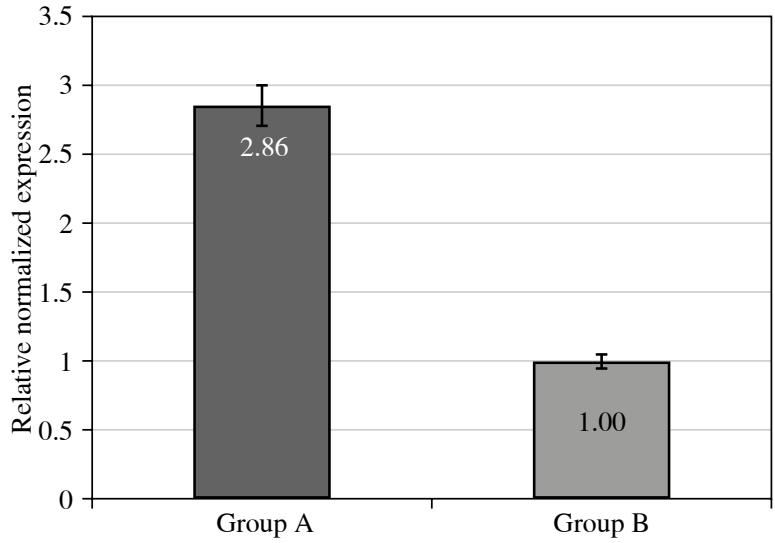

Fig. 2. Relative cDNA levels for GATA3 gene expression in eutopic endometrium of women with endometriosis and associated infertility (Group A), and control groups (Group B). Group A vs. Group B at $p$ level $<0.01$

[at $p<0.01$ ] increase of IL-2, INF- $\gamma$ TNF- $\alpha$, and IL-12 concentrations in the peritoneal fluid [44]). Increased level of T-bet expression in the endometrial samples of women with endometriosis and infertility can be explained by the necessity for Th1 activation connected with the destruction of endometrial tissue and development of the delayed type of hypersensitivity concerning ectopic transplants.

The mRNA level for the GATA3 gene in the endometrial samples of women with endometriosis was also significantly higher than that obtained for the control group, by a factor of 2.86 (Fig. 2).

These data correspond with the published studies reporting increased concentrations of certain cytokines produced by Th2 cells [16]. In our previous studies we have indicated clearly decreased IL-4 $(p<0.05)$ and significantly increased IL-6 $(p<0.01)$ in the peritoneal fluid samples. Chen et al. [38], in their study, reported the results in much lower levels of mRNA for T-bet gene than mRNA for GATA3 in the endometrial samples of women with endometriosis [38]. Interestingly, the results of our study indicate lower expression level of GATA3 than that of T-bet gene with increased mRNA levels for both TF when comparing to the control group $(p<0.01)$. The proportion 


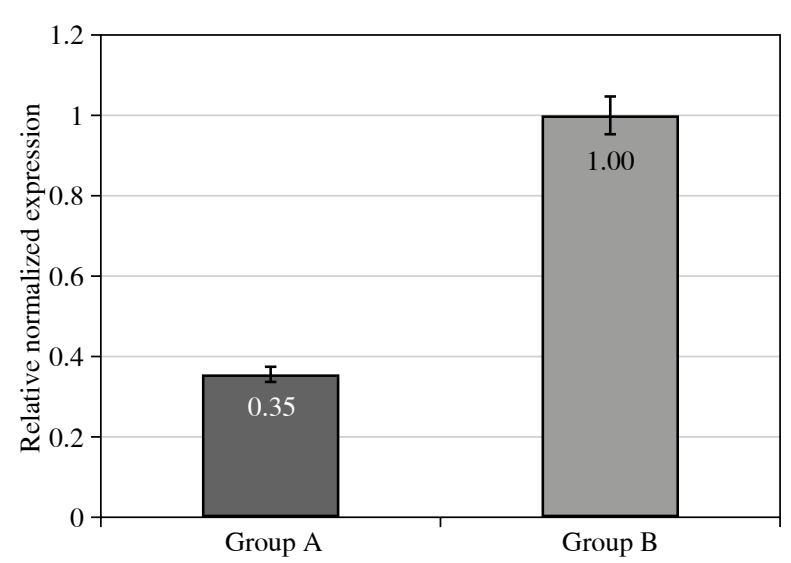

Fig. 3. Relative cDNA levels for Foxp3 gene expression in eutopic endometrium of women with endometriosis and associated infertility (Group A), and control group (Group B). Group A vs. Group B at $p$ level $<0.01$

of T-bet to GATA3 gene according to the data obtained was 1.31. It should be taken into account that our study was conducted in a small group, which does not allow us to draw firm conclusions, merely to show tendencies.

In the conducted study it was found that mRNA for Foxp3 gene in the eutopic endometrial samples of infertile women with endometriosis was markedly lower as compared to the gene expression found in a control group (Fig. 3).

In our view, the decreased mRNA for Foxp3 gene may reflect an insufficient function of regulatory T-lymphocytes. They could therefore maintain immunological tolerance towards endometrial ectopic transplants and promote their growth beyond the site of its physiological localisation. Our data correspond with well-known studies that indicate the presence of polymorphism of Foxp3 haplotypes connected with endometriosis [45]. However, there are studies indicating an increased mRNA level for Foxp3 in the endometrial samples of women with endometriosis; those studies were conducted under different conditions (in the preimplantation phase) [46]. On the other hand, susceptibility of the endometrium to implantation requires an adequate immunological tolerance in order to defend the embryo from the maternal immune response, and such neutrality may be disturbed in women with endometriosis [46-48].

There are reports indicating increased secretory phase Foxp3 regulatory cells in eutopic endometrium, indicating higher density of these cells in women with endometriosis, which then corresponded to increased density of Foxp3-positive cells in endometriotic ectopic sites [49]. It could be then speculated that during the secretory phase of women with endometriosis, uterine Tregs may exert their immunosuppressive effects on newly recruited immune cell populations, altering their function, such that during the time of menstruation, shed endometrial fragments are not efficiently targeted [50].
On the other hand, there are some reports showing that mRNA of Foxp3 gene in the endometrium of women with infertility of unknown origin is twice as low as that of healthy women, which indicates indirectly the role of T-regulatory lymphocytes in the development of infertility [51, 52].

Endometriosis associated with infertility is accompanied by increased expression of mRNA for T-bet and GATA3 genes with prevailing expression of T-bet in the endometrial eutopic tissue samples. In the endometrium of women with endometriosis associated with infertility a decreased level of mRNA for Foxp3 was observed, which may implicate its role both in the development of endometriosis and associated infertility. The data obtained stipulate the necessity of further studies concerning the role of T-lymphocytes in the pathogenesis of endometriosis and infertility in the context of their interaction with the other immune factors for possible diagnostic purpose and therapeutic aims in future.

The study has been conducted at Bukovinian State Medical University on the clinical base of the Centre for Infertility Treatment. Part of the study was performed at Danylo Halytskyi Lviv National University, while PCR of the endometrial samples was conducted at the molecular-genetic laboratory of Zaporizzhia State Medical University.

\section{Acknowledgements}

We express our gratitude to the Rector of Bukovinian State Medical University, Professor Boychuk Taras Mykolayovych, for his support and promotion the study; we are also grateful to the Director of the Centre of Treatment of Infertility, Professor Yuzko Oleksandr Mykhaylovych and Associate Professor Yuzko Tamara Anatoliyivna for their assistance and selection of patients on the base of the Centre.

The authors declare no conflict of interest.

\section{References}

1. Baskakov VP, Cvelev JV, Kira EF (2002): Jendometrioidnaja bolezn' Endometrioidnaya bol'ezn. Izdatel'stvo N-L 452: 13.

2. Cramer DW, Missmer SA (2002): The epidemiology of endometriosis. Ann N Y Acad Sci 955: 11-22.

3. McLeod BS, Retzloff MG (2010): Epidemiology of endometriosis: an assessment of risk factors. Clin Obstet Gynecol 53: 389-396

4. Adamjan LV, Kulakov VI, Andreeva EN (2006): Endometriozy. Medicina: 170.

5. Allaire C (2006): Endometriosis and infertility: a review. J Reprod Med 51: 164-168.

6. Juz'ko OM, Prijmak SG, Prijmak IA, Begal' LV (2005): Rehabilitation of reproductive function of women with infertility in endometriosis after laparoscopic surgery. Shpital'na hirurgija 2: 94-98.

7. Savickij GA, Gorbushin SM (2002): Peritoneal endometriosis and infertility (clinical and morphological studies). JeLBISPb: 170 . 
8. Burney RO, Giudice LC (2012): Pathogenesis and pathophysiology of endometriosis. Fertil Steril 98: 511-519.

9. Vinatier D, Orazi G, Cosson M, et al. (2001): Theories of endometriosis. Eur J Obstet Gynecol Reprod Biol 96: 21-34.

10. Acién P, Velasco I (2013): Endometriosis: a disease that remains enigmatic. ISRN Obstet Gynecol 2013: 242149.

11. Kyama CM, Debrock S, Mwenda JM, et al. (2003): Potential involvement of the immune system in the development of endometriosis. Reprod Biol Endocrinol 1: 123.

12. Richter ON, Dorn C, Rösing B, et al. (2005): Tumor necrosis factor alpha secretion by peritoneal macrophages in patients with endometriosis. Arch Gynecol Obstet 271: 143-147.

13. Koninckx PR, Craessaerts M, Timmerman D, et al. (2008): Anti-TNF-alpha treatment for deep endometriosis-associated pain: a randomized placebo-controlled trial. Hum Reprod 23: 2017-2023.

14. Somigliana E, Viganň $P$, Rossi G, et al. (1999): Endometrial ability to implant in ectopic sites can be prevented by interleukin-12 in a murine model of endometriosis. Hum Reprod 14: 2944-2950.

15. Itoh H, Sashihara T, Hosono A, et al. (2011): Interleukin-12 inhibits development of ectopic endometriotic tissues in peritoneal cavity via activation of NK cells in a murine endometriosis model. Cytotechnology 63: 133-141.

16. Ou Yang Z, Hirota Y, Osuga Y, et al. (2008): Interleukin-4 stimulates proliferation of endometriotic stromal cells. Am J Pathol 173: 463-469.

17. Sinaii N, Cleary SD, Ballweg ML, et al. (2002): High rates of autoimmune and endocrine disorders, fibromyalgia, chronic fatigue syndrome and atopic diseases among women with endometriosis: a survey analysis. Hum Reprod 17: 2715-2724.

18. Coomes SM, Pelly VS, Wilson MS (2013): Plasticity within the $\alpha \beta^{+} \mathrm{CD} 4^{+} \mathrm{T}$-cell lineage: when, how and what for? Open Biol 3: 120157.

19. Yang XO, Nurieva R, Martinez GJ, et al. (2008): Molecular antagonism and plasticity of regulatory and inflammatory $\mathrm{T}$ cell programs. Immunity 29: 44-56.

20. Wong WF, Kohu K, Chiba T, et al. (2011): Interplay of transcription factors in T-cell differentiation and function: the role of Runx. Immunology 132: 157-164.

21. Dong C (2008): TH17 cells in development: an updated view of their molecular identity and genetic programming. Nat Rev Immunol 8: 337-348.

22. Naito T, Tanaka H, Naoe Y, et al. (2011): Transcriptional control of T-cell development. Int Immunol 23: 661-668.

23. Evans CM, Jenner RG (2013): Transcription factor interplay in Thelper cell differentiation. Brief Funct Genomics 12: 499-511.

24. Murphy KM, Reiner SL (2002): The lineage decisions of helper T cells. Nat Rev Immunol 2: 933-944.

25. Kemp KL, Levin SD, Bryce PJ, et al. (2010): Lck mediates Th2 differentiation through effects on T-bet and GATA-3. J Immunol 184: 4178-4184.

26. Usui T, Nishikomori R, Kitani A, et al. (2003): GATA-3 suppresses Th1 development by downregulation of Stat 4 and not through effects on IL-12Rbeta2 chain or T-bet. Immunity 18 : 415-428.

27. Ouyang W, Löhning M, Gao Z, et al. (2000): Stat6-independent GATA-3 autoactivation directs IL-4-independent Th2 development and commitment. Immunity 12: 27-37.

28. Fontenot JD, Rasmussen JP, Williams LM, et al. (2005): Regulatory $\mathrm{T}$ cell lineage specification by the forkhead transcription factor foxp3. Immunity 22: 329-341.
29. Ivanov II, McKenzie BS, Zhou L, et al. (2006): The orphan nuclear receptor RORgammat directs the differentiation program of proinflammatory IL-17+ T helper cells. Cell 126: 1121-1133.

30. Ichiyama K, Yoshida H, Wakabayashi Y, et al. (2008): Foxp3 inhibits RORgammat-mediated IL-17A mRNA transcription through direct interaction with RORgammat. J Biol Chem 283: 17003-17008.

31. Skapenko A, Leipe J, Niesner U, et al. (2004): GATA-3 in human T cell helper type 2 development. J Exp Med 199: 423-248.

32. Chakir H, Wang H, Lefebvre DE, et al. (2003): T-bet/GATA3 ratio as a measure of the Th1/Th2 cytokine profile in mixed cell populations: predominant role of GATA-3. J Immunol Methods 2278: 157-169.

33. Li X, Sun Q, Zhang M, Chen J, Liu Z (2013): The diagnostic value of transcription factors T-bet/GATA3 ratio in predicting antibody-mediated rejection. Clin Dev Immunol 2013: 460316.

34. Kanwar B, Favre D, McCune JM (2010): Th17 and regulatory T cells: implications for AIDS pathogenesis. Curr Opin HIV AIDS 5: 151-157.

35. Lin ZW, Wu LX, Xie Y, et al. (2015): The expression levels of transcription factors T-bet, GATA-3, ROR $\gamma \mathrm{t}$ and FOXP3 in peripheral blood lymphocyte (PBL) of patients with liver cancer and their significance. Int J Med Sci 12: 7-16.

36. Saito S, Nakashima A, Shima T, et al. (2010): Th1/Th2/Th17 and regulatory T-cell paradigm in pregnancy. Am J Reprod Immunol 63: 601-610.

37. Chaouat G (2007): The Th1/Th2 paradigm: still important in pregnancy? Semin Immunopathol 29: 95-113.

38. Chen P, Zhang Z, Chen Q, et al. (2012): Expression of Th1 and Th2 cytokine-associated transcription factors, T-bet and GATA-3, in the eutopic endometrium of women with endometriosis. Acta Histochem 114: 779-784.

39. Szabo SJ, Sullivan BM, Peng SL, et al. (2003): Molecular mechanisms regulating Th1 immune responses. Annu Rev Immunol 21: 713-758.

40. Szabo SJ, Kim ST, Costa GL, et al (2000): A novel transcription factor, T-bet, directs Th1 lineage commitment. Cell 100: 655-669.

41. Afkarian M, Sedy JR, Yang J, et al. (2002): T-bet is a STAT1induced regulator of IL-12R expression in nadve CD4+ T cells. Nat Immunol 3: 549-557.

42. Usui TJC, Preiss Y, Kanno ZJ, et al. (2006): T-bet regulates Th1 responses through essential effects on GATA-3 function rather than on IFNG gene acetylation and transcription. J Exp Med 203: 755-766.

43. Fairbanks F, Abrăo MS, Podgaec S, et al. (2009): Interleukin-12 but not interleukin-18 is associated with severe endometriosis. Fertil Steril 91: 320-324.

44. Koval HD, Pashkovskaja NV, Olenovich OA, et al. (2013): Peculiarities of Systemic and Local Production of Anti-inflammatory Cytokines in Women with Endometriosis Associated with Infertility. Collected papers of the International Scientific Conference "Modern Studies of Medical-Biological Sciences: Improvement of Diagnostics, Elaboration of Preventive Measures and Therapy of Diseases". Russia, Kirov, June 26-28: 67-73.

45. André GM, Barbosa CP, Teles JS, et al. (2011): Analysis of FOXP3 polymorphisms in infertile women with and without endometriosis. Fertil Steril 95: 2223-2227. 
46. Chen S, Zhang J, Huang C, et al. (2012): Expression of the T regulatory cell transcription factor FoxP3 in peri-implantation phase endometrium in infertile women with endometriosis. Reprod Biol Endocrinol 10: 34.

47. Mor G, Cardenas I, Abrahams V, et al. (2011): Inflammation and pregnancy: the role of the immune system at the implantation site. Ann N Y Acad Sci 1221: 80-87.

48. Tilburgs T, Claas FH, Scherjon SA (2010): Elsevier trophoblast research award lecture: unique properties of decidual $\mathrm{T}$ cells and their role in immune regulation during human pregnancy. Placenta 31: 82-86.

49. Berbic M, Hey-Cunningham AJ, Ng C, et al. (2010): The role of Foxp3+ regulatory T-cells in endometriosis: a potential controlling mechanism for a complex, chronic immunological conditio. Hum Reprod 25: 900-907.

50. Matarese G, De Placido G, Nikas Y, et al. (2003): Pathogenesis of endometriosis: natural immunity dysfunction or autoimmune disease? Trends Mol Med 9: 223-228.

51. Teles A, Schumacher A, Kühnle MC, et al. (2013): Control of Uterine Microenvironment by Foxp3+ Cells Facilitates Embryo Implantation Front Immunol 4: 1-12.

52. Jasper MJ, Tremellen KP, Robertson SA (2006): Primary unexplained infertility is associated with reduced expression of the T-regulatory cell transcription factor Foxp3 in endometrial tissue. Mol Hum Reprod 12: 301-308. 